\title{
New vistas on NO-cGMP signalling
} John Garthwaite*

\author{
Address: Wolfson Institute for Biomedical Research, University College London, Gower Street, London WC1E 6BT, UK \\ Email: John Garthwaite* - john.garthwaite@ucl.ac.uk \\ * Corresponding author
}

from 2nd International Conference of cGMP Generators, Effectors and Therapeutic Implications

Potsdam, Germany, 10-12 June, 2005

Published: 16 June 2005

BMC Pharmacology 2005, 5(SuppI I):S2 doi:I0.1 186/I47I-22I0-5-SI-S2

Recognition that a biochemically familiar enzyme called (in homogenate terms) soluble guanylyl cyclase (GC), serves as the major physiological receptor for NO immediately raises a host of questions concerning how this receptor transduces NO signals in the many different cells in which it is found. Simply calling it a receptor (which it is) is helpful in bringing into play a wealth of theoretical and practical knowledge built up over decades to describe and understand the principles of biological signalling mechanisms. Viewed in this context, much of the most basic information about the operation of GC-coupled NO receptors was missing or incoherent. During the last few years, we and others have tried to rectify this situation. Devising methods for supplying NO in known, constant concentrations $[1,2]$ was a prerequisite for carrying out meaningful experiments. Measurement of the potency of NO for activating GC and of the rates of activation and deactivation has now permitted the introduction of a simple but realistic kinetic model [3]. The receptors in cells can detect very brief NO signals (millisecond range) because they activate and deactivate with subsecond kinetics, and they can also detect very low NO concentrations (subnanomolar) There are, however, a number of important differences in the way that the receptors behave in cells versus cell-free preparations. For example, in homogenates or with the purified protein, $\mathrm{NO}$ is about 10-fold more potent as an agonist than it is in intact cells and, unlike in cells, NO-evoked GC activity does not desensitize. The possible role of a number of endogenous factors in shaping NO-evoked GC activity in cells will be discussed.

\section{Acknowledgements}

Supported by The Wellcome Trust and The Sir Jules Thorn Charitable Trust.

\section{References}

I. Bellamy TC, Griffiths C, Garthwaite J: Differential sensitivity of guanylyl cyclase and mitochondrial respiration to nitric oxide measured using clamped concentrations. I Biol Chem 2002, 277:3I80I-3I807.

2. Griffiths C, Wykes V, Bellamy TC, Garthwaite J: A new and simple method for delivering clamped NO concentrations in the physiological range: application to activation of guanylyl cyclase-coupled NO receptors. Mol Pharmacol 2003, 64:1349-1356.

3. Garthwaite J: Dynamics of cellular NO-cGMP signalling. Front Biosci 2005, 10:|868-|880. 